\title{
Occupational Health Issues among Police Personnel: An Exploratory Study
}

\section{Singh LP*}

Department of Industrial and Production Engineering, Dr. B.R. Ambedkar National Institute of Technology, India

*Corresponding author: Lakhwinder Pal Singh, Department of Industrial and production Engineering, Dr. B. R. Ambedkar NIT, Jalandhar 144011, India, Email: singhl@nitj.ac.in

\section{Research Article \\ Volume 3 Issue 6}

Received Date: November 25, 2019

Published Date: December 30, 2019

DOI: $10.23880 /$ eoij-16000223

\section{Abstract}

Background: Among the 11 million cases of occupational diseases globally, 1.9 (17\%) million cases are contributed by India. Most studies on occupational health in India are done in industrial settings, whereas few studies have looked into other occupational groups. Police personnel by nature of their job are continuously exposed to toxic pollutants, noise from automobiles and long working hours of standing, poor posture, poor work centre design etc. throughout their job. This study aimed to investigate the occupationally induced health problems (respiratory problems, musculoskeletal and hearing problems) among police personnel in Jalandhar city and to find out the factors associated with them.

Methodology: Quantitative research model in the form of prospective type survey design was selected for this study. Total 160 subjects were selected from Police department of Jalandhar City based on non-probability convenience sampling. Data was collected using questionnaire including questions on respiratory problems, low back pain and noise induced hearing loss respectively. Descriptive statistic and chi square was used for data analysis.

Results: The prevalence of overall respiratory problems, low back pain, and noise induced hearing loss was $64 \%$, $68 \%$ and $46 \%$ respectively. Work related factors like number of service years, type of duty, posting location, nature of shift, working hours near roadside per day were significantly associated with the outcome. Lack of proper use of protective aids (face masks, hearing aids) contributes to respiratory and hearing problems. Improper design of car seat, duty belt, improper posture and driving also contributes in low back pain.

Conclusion: Police personnel have significantly higher prevalence of occupational health problems. They should be educated on ergonomics, posture, working hour breaks in between work, use of protective aids to improve healthy life and performance in duty.

Keywords: Respiratory problems; Low back pain; Noise induced hearing loss; Police personnel 


\section{Ergonomics International Journal}

Abbreviations: COPD: Chronic Obstructive Pulmonary disease; MSDs: Musculoskeletal Disorders; LBP: Low Back Pain; NIHL: Noise Induced Hearing Loss; PPE: Personal Protective Equipment; SAHI: Society of Aid and Hearing Impaired.

\section{Introduction and Literature}

According to WHO (2013) Occupational lung diseases is a major contributor of the global occupational disease burden and is a main focus of occupational health programs worldwide. Work-related occupational exposure to air borne particulates accounts for about 386000 deaths and nearly 6.6 million [1]. The bulk of this is contributed by Chronic Obstructive Pulmonary disease (COPD) followed by asthma and pneumoconiosis. In industrial settings, workers are also found with respiratory symptoms [2]. The traffic police personnel are exposed to significant amounts of traffic related ambient air pollution, are detected for mainly chronic respiratory diseases like chronic cough, chronic phlegm, wheezing, Dyspnea along with decreased lung function [3-5]. It has been established that major share of the traffic related air pollution is due to the emissions from automobiles which in many cities of the developing world do not follow emission standards. Rapid industrialization and urbanization have aggravated the rising levels of ambient air pollution in the cities especially in the developing countries including the Asian countries. The most commonly reported respiratory symptoms associated with traffic pollution in children as well as among occupational groups exposed to traffic pollution include bronchitis, asthma, wheezing, breathlessness, dry cough and cough with phlegm, reduced lung functions and other nasal problems [6,7]. The respiratory diseases due to traffic pollution get increased with time. The initial acute symptoms due to air pollution get worsen and cause chronic respiratory problems. Police personnel posted in the traffic duty are exposed to these pollutants for 6-8 hours a day. Those who are exposed to traffic for longer period of time have increased respiratory problems [8]. The traffic police as well as law and order police personnel are the worst sufferers because by nature of their job, they are continuously exposed to the toxic pollutants emitted from the automobiles. Therefore, they are more prone to like bronchitis, pneumonia, decreased lung function and even other health problems which include hearing impairment, eye related problems, etc. [9]. However, previously [5] did a comparative cross sectional study in Jalgon city, India among 60 nonsmoking traffic police and 60 healthy young adults showed $40 \%$ of traffic police had frequent cough, $10 \%$ had shortness of breath and $27 \%$ suffered from irritation in respiratory tract. Singh V Sharma, et al. [10] Satapathy D, et al. [11], Gupta s, et al. [12]studied that among traffic police in India also showed decreased lung function and its evident with increase duration of work period. Most of the above mentioned studies have presented their results on the basis of relatively small sample size ranging from 30 to 80. Karita K, et al. [13] did a study and found that factors like duration of work hours, years of residential living in polluted cities also contributes to the respiratory problems. Longer the duration of these factors more worsen is the problem.

In case of musculoskeletal disorders (MSDs) Lee, et al. (2012) [6] in his study discussed that back muscles act to support the spine and maintain the stability of the spine; weakness of back muscles can lead to low back pain and is known as a main cause of recurrence. Generally we found that people stand for long time from morning to night continuously, but the sitting or standing system is poor, most of the cases poor posture can lead to pain. The back is not supported; as a result their lumbar spine stays incorrect position resulting various ligament structures on full stretch. Traffic police have to do all type of activities themselves to maintain the traffic. These types of activity include lifting, twisting \& repeated movements of the spine. As far as low back pain (LBP) is concerned, different officers arranged the equipment on their belts in different ways. Arranging the equipment anteriorly on the belt was associated with the largest increase in LBP. On the other side, the typical postures \& activities of traffic police make them one of the most vulnerable groups of being LBP. They bend frequently, twist right \& left, \& transfer the standing systems of the traffic police are inappropriate, without back support Most of the cases the posture is too poor to cause the LBP.

Traffic police personnel are also found at an increased risk of noise induced hearing loss (NIHL) for the environmental noise exposure. Prevalence of occupational noise induced hearing loss amongst traffic police personnel and found that a very significant number (81.2\%) showed sensor neural hearing loss [14]. Occupational noise induced hearing loss and hearing threshold profile at high frequencies and concluded that Prevalence of hearing loss symptom and hearing thresholds were more in exposed group than in control group. There has been a significant hearing loss at high frequency as compared to lower ones. Audiometer revealed notch at $4 \mathrm{kHz}$ with less effect at 6 or $8 \mathrm{kHz}$, cumulative effect of duration of exposure. 


\section{Ergonomics International Journal}

In a study to assess the prevalence of hearing loss in police constable and officers working in heavy traffic areas $60 \mathrm{~dB}(\mathrm{~A})$ and to correlate the hearing loss with duration exposure to noise. It was found that, tearing loss is very common in police constables and police officers who are working in heavy traffic zones [15].

Dennis Marcus Mathew also conducted a sample survey on effect of noise pollution on traffic policemen of Hyderabad city, carried out by Society of Aid and Hearing Impaired (SAHI), the findings of the study indicate that $76 \%$ of 45 cops screened, had noise induced auditory effects and among these had completed 5 years in traffic wing had hearing loss in various degrees. The traffic policemen do not use any personal protective equipment (PPE) and have varying degree of hearing loss due to longer period exposure to noise pollution. In Varanasi city about traffic noise pollution on exposed people, showed that $85 \%$ of people were disturbed by traffic noise, $90 \%$ of people are reported that noise is main cause of headache, high BP, dizziness and fatigue and interfering the daily activities [16].

\section{Methodology}

In this study, a comprehensive questionnaire was formulated to assess all the information regarding various hazardous parameters data was collected through questionnaire, with prior consent from the participants. The questionnaire included demographic description, questions relating to low back pain, respiratory problems and noise induced hearing loss. Demographic data details includes age, gender, address, height/weight, marital status, level of education, Current department of work, years of service completed in department. The subjective data collected was analyzed using SPSS version 17 software.

\section{Results}

\section{Socio-Demographic Information}

The study was conducted on 160 police personnel of Jalandhar city. Out of the participants 131 (82\%) were male and $29(18 \%)$ were female. Among the participants $27(17 \%)$ were under the age of 30 years, $33(21 \%)$ were in the range of $31-40$ years, $83(52 \%)$ were in the range of 41-50 years and $17(11 \%)$ were above 50 years of age. Higher number of participants $83(52 \%)$ were in the range of 41-50 years of age. Out of $160132(83 \%)$ were married and $28(18 \%)$ were unmarried. Body type (BMI) of the participants $91(57 \%)$ were normal body type and $69(43 \%)$ were overweight (Table 1$)$.

\begin{tabular}{|c|c|c|c|}
\hline \multirow{2}{*}{ Variables } & Opts & Frequency(n) & Percentage (\%) \\
\hline \multirow{2}{*}{ Gender } & Male & 131 & $82 \%$ \\
\cline { 2 - 4 } & Female & 29 & $18 \%$ \\
\hline \multirow{3}{*}{ Age (in years) } & Under 30 & 27 & $17 \%$ \\
\cline { 2 - 4 } & $31-40$ & 33 & $52 \%$ \\
\cline { 2 - 4 } & $41-50$ & 83 & $11 \%$ \\
\cline { 2 - 4 } & Over 50 & 17 & $83 \%$ \\
\cline { 2 - 4 } & Married & 132 & $18 \%$ \\
\hline \multirow{2}{*}{ Marital Status } & Unmarried & 28 & $57 \%$ \\
\cline { 2 - 4 } & Normal & 91 & $43 \%$ \\
\hline \multirow{2}{*}{ BMI } & Overweight & 69 & \\
\end{tabular}

Table 1: Socio Demographic Information.

\section{Work Related Factors}

Work related factors like type of duty, frequent posting location, year of service, working hours per day, number of working hours near road side, frequent shift posted were looked into. Among total respondents (160), $51(32 \%)$ were from administration duty and more than half of the respondents 109 (68\%) were from field job. Out of $109,47(29 \%)$ did traffic duty and $62(30 \%)$ did patrolling duty. As per posting location 66(41\%) were posted at crowded junctions, 44(28\%) were posted at highways and $50(31 \%)$ were posted at other locations like offices etc.

Number of years of service of the police personnels was divided into 5 categories. Out of 160 respondents $14(9 \%)$ were in 0 - 4 years of service, $32(20 \%)$ were in 5 9 years of services, $15(9 \%)$ were in 10-14 years of service, $18(11 \%)$ were in 15- 19 years of services and maximum number of respondents $81(51 \%)$ were in service for more than 20 years. All the 160 police 
personnel worked for more than 6 hours per day. Among them 52(32\%) worked near roadside for less than 6 hours and 108(68\%) worked for more than 6 hours near the roadside. According to nature of shift, 52(33\%) gave 24 hours duty i.e. for all the three shifts. 12 (8\%) worked in morning shift, 36(23\%) in afternoon shift, 35(22\%) in night shift. $20(13 \%)$ worked for 2 shifts i.e. morning and night, 5(3\%) worked for afternoon and night shift (Table 2).

\begin{tabular}{|c|c|c|c|}
\hline Variables & Opts & Frequency(n) & Percentage (\%) \\
\hline \multirow{3}{*}{ Type of Duty } & Traffic duty & 47 & $29 \%$ \\
\hline & Patrolling Duty & 62 & $39 \%$ \\
\hline & Administration & 51 & $32 \%$ \\
\hline \multirow{3}{*}{ Posting location } & Crowded Junctions & 66 & $41 \%$ \\
\hline & Highways & 44 & $28 \%$ \\
\hline & Others & 50 & $31 \%$ \\
\hline \multirow[t]{3}{*}{ Year of Service } & 10-14years & 15 & $9 \%$ \\
\hline & 15-19years & 18 & $11 \%$ \\
\hline & Over 20years & 81 & $51 \%$ \\
\hline \multirow{2}{*}{ Working hours per day } & $<$ <6hours & 0 & $0 \%$ \\
\hline & $>6$ hours & 160 & $100 \%$ \\
\hline \multirow{5}{*}{ Nature of shift posted } & Afternoon & 36 & $23 \%$ \\
\hline & Night & 35 & $22 \%$ \\
\hline & Morning and Night & 20 & $13 \%$ \\
\hline & Afternoon and Night & 5 & $3 \%$ \\
\hline & All the three shifts & 52 & $33 \%$ \\
\hline
\end{tabular}

Table 2: Characteristics of study sample based on work related factors.

\section{Prevalence of Respiratory Problems}

Among all of the 160 participants, 103(64\%) participants had been suffered from respiratory problems and 57(36\%) participants had not been suffered from respiratory problems (Table 3).

\begin{tabular}{|c|c|c|c|}
\hline Variables & Opts & Frequency & Percentage \\
\hline \multirow{2}{*}{ Respiratory Problem } & No & 57 & $36 \%$ \\
\cline { 2 - 4 } & Yes & 103 & $64 \%$ \\
\hline
\end{tabular}

Table 3: Prevalence of overall Respiratory Problem among Police Personnel.

\section{Prevalence of Low Back Pain}

Among all of the 160 participants $109(68 \%)$ participants had been suffered from LBP and 51 (32\%) participants had not been suffered from LBP (Table 4).

\begin{tabular}{|c|c|c|c|}
\hline Variables & Opts & Frequency & Percentage \\
\hline \multirow{2}{*}{ Low Back Pain } & Yes & 109 & $68 \%$ \\
\cline { 2 - 4 } & No & 51 & $32 \%$ \\
\hline
\end{tabular}

Table 4: Prevalence of low back pain among the police personnel. 


\section{Ergonomics International Journal}

\section{Prevalence of Noise Induced Hearing Loss}

Among all of the 160 respondents 73(46\%) suffered from noise induced hearing loss and $87(54 \%)$ had not been suffered from this problem (Table 5).

\begin{tabular}{|c|c|c|c|}
\hline Variables & Opts & Frequency & Percentage \\
\hline \multirow{2}{*}{ Noise Induced hearing Loss } & Yes & 73 & $46 \%$ \\
\cline { 2 - 3 } & No & 87 & $54 \%$ \\
\hline
\end{tabular}

Table 5: Prevalence of noise induced hearing loss among police personnel.

\section{Conclusion}

The present study concludes that occupational health problems are very common in police personnel. The results showed that prevalence of respiratory problems, low back pain and noise induced hearing loss was 64\%, $68 \%$ and $46 \%$ respectively. The frequency and intensity of these problems is related to the physical requirements of the job. Possible risk factors include age, year of service, type of duty, working hours, working posture, improper use of protective equipment etc.

\section{Recommendations}

It is seen that lack of awareness and guidance of the tasks undertaken is the main reason for existing health problems. Police personnel should be educated on ergonomics, posture, working hour breaks in between work, use of protective aids to improve healthy life and performance in duty.

Ergonomic interventions are necessary to prevent the complaints of low back pain. The existence of a positive association between ergonomic problems and LBP implies that even modest modifications could result in a significant decrease in frequency of problems.

\section{References}

1. Driscoll T, Nelson DI, Steenland K, Leigh J, ConchaBarrientos M, et al. (2005) The global burden of nonmalignant respiratory disease due to occupational airborne exposures. Am J Ind Med 48(6): 432-445.

2. Singh LP, Bhardwaj A, Deepak KK (2013) Occupational Exposure to Respirable Suspended Particulate Matter and Lung Functions Deterioration of Steel Workers: An Exploratory Study in India. ISRN Public Health.

3. Kumar NVN, Babu PS, Nagarjuna A (2009) Health hazards of traffic police occupationally exposed to automobile exhaust pollutants in tirupatipilgrim town. An international journal of environmental sciences 3(1): 189-197.

4. Pal P, John RA, Dutta TK, Pal GK (2010) Pulmonary function test in traffic police personnel in Pondicherry. Indian J Physiol Pharmacol 54(4): 329336.

5. Ingle ST, Pachpande BG, Wagh ND, Patel VS, Attarde SB (2005) Exposure to vehicular pollution and respiratory impairment of traffic policemen in Jalgaon City, India. Ind Health 43(4): 656-662.

6. Lee YL, Shaw CK, Su HJ, Lai JS, Ko YC, et al. (2003) Climate, traffic-related air pollutants and allergic rhinitis prevalence in middle-school children in Taiwan. Eur Respir J 21(6): 964-970.

7. Anderson GS, Zutz A, Plecas DB (2011) Police officer back health. The Journal of Criminal Justice Research 2(1): 100-110.

8. Mauer MP, Cummings KR, Carlson GA (2007) Health Effects in New York State Personnel Who Responded to the World Trade Center Disaster. JOEM 49(11): 1197-205.

9. Sreedevi V, Rao VD, Gopal HVV, Prasad SV, Devi S, et al. (2009) Cytogenetic evaluation of traffic policemen occupationally exposed to vehicular exhaust. Indian J Med Res 130(5): 520-525.

10. Singh V, Sharma BB, Yadav R, Meena P (2009) Respiratory morbidity attributed to auto-exhaust pollution in traffic policemen of Jaipur, India. J Asthma 46(2): 118-121.

11. Satapathy D, Behera T, Tripathy R (2009) Health status of traffic police personnel in brahmapur city. Indian J Community Med 34(1): 71-72.

12. Gupta D, Aggarwal AN, Chaudhry K, Chhabra SK, D"Souza GA, et al. (2006) Household environmental tobacco smoke exposure, respiratory symptoms and 


\section{Ergonomics International Journal}

asthma in non-smoker adults: a multicentric population study from India. Indian J Chest Dis Allied Sci 48(1): 31-36.

13. Karita K, Yano E, Tamura K, Jinsart W (2004) Effects of working and residential location areas on air pollution related respiratory symptoms in policemen and their wives in Bangkok, Thailand. Eur J Public Health 14(1): 24-26.

14. Sinha RK (1993) Automobile pollution in India and its human impact. Environmentalist 13(2): 111-115.
15. Mitta Sreeniva Sulu (2016) Survey and cross sectional study on noise induced hearing loss of police constables and officers working in heavy traffic areasanindian perspective. International Journal of Otorhinolaryngology and Head \& Neck Surgery (TJPRC: IJOHNS) 1(2): 17-20.

16. Chattopadhyay Bhaskar (2015) Exposure to vehicular pollution and assessment of respiratory function inurban residents. 